\title{
REDACTIONEEL
}

\section{Toezien op publieke belangen}

Dit nummer is gewijd aan het rapport Toezien op publieke belangen. Naar een verruimd perspectief op rijkstoezicht van de Wetenschappelijke Raad voor het Regeringsbeleid (WRR). Hierin analyseert de Raad de vele uitdagingen waar toezichthouders van de rijksoverheid (inspecties, markttoezichthouders) in complexe en snel veranderende maatschappelijke omstandigheden mee geconfronteerd worden. Centraal staat daarbij de vraag hoe de overheid en haar toezicht in beleid en praktijk reageren op die uitdagingen en hoe de maatschappelijke meerwaarde van het toezicht kan worden vergroot.

Uit het rapport komt het beeld naar voren van toezicht dat aan allerlei verschillende - en veelal tegenstrijdige - verwachtingen en belangen (vanuit de politiek, de burger, de onder toezicht gestelde, het bestuur) tegemoet moet komen. De WRR signaleert in dit verband een 'toezichtparadox': minder toezicht als het goed gaat en méér als iets misloopt. Toezichthouders krijgen ook in toenemende mate te maken met onder toezicht gestelden die veel machtiger zijn geworden en die bereid en ook in staat zijn hun belangen in rechte te verdedigen. Volgens de WRR overheersten in het afgelopen decennium drie oriëntaties ten aanzien van toezicht:

- de nadruk op lasten en kosten, waarbij het terugdringen van de administratieve en financiële lasten voor overheid en veld centraal staat;

- de nadruk op naleving van wet- en regelgeving en daarop gerichte handhavingsinterventies;

- de nadruk op de politiek-bestuurlijke functie, met als uitgangspunt dat het toezicht een verlengstuk is van bestuur en beleid en bewaakt dat vastgesteld beleid daadwerkelijk wordt uitgevoerd.

Hij acht deze oriëntaties op zich relevant en legitiem, maar te beperkt om adequaat te kunnen (blijven) inspelen op de snelle technologische en maatschappelijke ontwikkelingen en de steeds hoger gespannen verwachtingen. Ze hebben te weinig oog voor de meerwaarde en de opbrengsten van toezicht, inclusief de bijdragen aan het borgen of realiseren van publieke belangen, en ze bieden onvoldoende tegenspel tegen de misvatting dat maximale naleving 100 procent veiligheid oplevert. Daarom pleit de WRR voor een verruiming van het perspectief; voor een bredere blik op het rijkstoezicht die verder kijkt dan de incidenten van vandaag en meer recht doet aan de maatschappelijke complexiteit en dynamiek. De Raad onderscheidt vier kernopgaven van zo'n ruimer perspectief:

1. neem publieke belangen als uitgangspunt bij toezichtvraagstukken;

2. breng de gewenste en gerealiseerde maatschappelijke opbrengsten van toezicht beter in kaart, zodat die adequaat tegen kosten en lasten kunnen worden afgewogen; 
3. speel explicieter in op de governancestructuur in een toezichtdomein zoals die naar voren komt uit een analyse van het gehele maatschappelijke krachtenveld in dat domein;

4. verstevig de reflectieve functie van toezicht.

Hij formuleert vervolgens een drietal kernwaarden van goed toezicht die de condities zouden moeten vormen om aan dat verruimde perspectief invulling te kunnen geven: onpartijdigheid, onafhankelijkheid en transparante publieke verantwoording. Dit zou dan, kort gezegd, toezichthouders moeten opleveren die met gezag, overtuigingskracht en los van de politieke waan van de dag kunnen opereren.

Het rapport laat volgens de redactie zien dat er dringend behoefte is aan een grondige maatschappelijke én politieke discussie over de toekomst van het overheidstoezicht. Tot die discussie geeft de WRR een goede aanzet, in het bijzonder door de verrichte analyse van de 'staat van het toezicht' en de dilemma's waarvoor het toezicht staat, en door de geformuleerde kernwaarden en de gedane aanbevelingen. Wel tekent de redactie hierbij aan het jammer en niet logisch te vinden dat de WRR zich heeft beperkt tot het rijkstoezicht. Ook op bovennationaal en decentraal niveau wordt immers toezicht verricht op publieke belangen. De discussie en politieke besluitvorming over het rapport zullen, wat de redactie betreft, dan ook moeten leiden tot een eenduidig verruimd perspectief op toezicht op publieke belangen op alle overheidsniveaus.

Het is volgens de redactie van belang dat hierbij door alle betrokkenen wordt onderkend en erkend dat er sprake is van een emancipatie van het toezicht, in tweeërlei betekenis. Om te beginnen laat het rapport van de WRR duidelijk zien dat in de afgelopen twintig jaar het houden van toezicht op publieke belangen een aparte professie binnen de overheidsdienst is geworden, te onderscheiden van het maken en uitvoeren van beleid. Parallel hieraan tekent zich de afgelopen jaren steeds sterker een eigenstandige positie van het toezicht af, naast de uitvoerende macht. De WRR geeft daartoe wel een aanzet door het toezicht in zijn rapport als een basisinstitutie aan te merken, ${ }^{1}$ maar werkt dit punt uiteindelijk niet uit. Dit is jammer. Volgens de heersende staatsrechtelijke opvattingen hoort toezicht thuis bij de uitvoerende macht (trias politica). Deze kijk is echter aan herziening toe, nu sinds het einde van de vorige eeuw door de Europese en Nederlandse wetgever en ook in de literatuur in toenemende mate het belang van een onafhankelijke positie van toezichthouders wordt erkend als een voorwaarde voor effectief en vertrouwenwekkend toezicht met waarborgen voor een gelijk speelveld voor ondernemingen. Met name door de instelling van onafhankelijke markttoezichthouders, functionerend onder de politieke verantwoordelijkheid van een minister, is een ontwikkeling in de richting van een 'toezichthoudende macht' ingezet. De introductie van een punitieve bevoegdheid voor toezichthouders, buiten de rechter om - in de vorm van een bestuurlijke boete of een bestuurlijke strafbeschikking -, past in deze ontwikkeling. Met de uitvoerende macht heeft deze nieuwe 'macht' gemeen dat een rechtstreekse verantwoording over haar handelen 
aan een hiervoor aangewezen vertegenwoordigend politiek orgaan moet zijn gewaarborgd. Met de rechtsprekende macht heeft zij gemeen dat een onafhankelijke en objectieve oordeelsvorming over geconstateerde overtredingen en wat hierop een passende reactie is, moet zijn gewaarborgd.

Voorts hoopt de redactie dat de discussie en politieke besluitvorming ook zullen leiden tot duidelijkheid over de vraag wie binnen de regering verantwoordelijk wordt voor een samenhangende implementatie van het verruimde perspectief op toezicht op publieke belangen en voor het stelsel van de 'toezichthoudende macht'. De WRR heeft zich hierover niet uitgesproken.

Aan het vervolg op het WRR-rapport wil de redactie van dit multidisciplinaire tijdschrift op verschillende manieren bijdragen: (1) door de hoofdzaken van het rapport mede richting te laten geven aan het redactiebeleid, (2) door iedereen die in het toezichtveld werkzaam is, via het tijdschrift uit te nodigen om kennis te nemen van het rapport en een reactie hierop te geven en hiermee in de eigen situatie aan de slag te gaan, en (3) door personen uit de wereld van het toezicht vanuit verschillend perspectief aan het woord te laten over hoofdzaken van het rapport en de WRR de gelegenheid te bieden tot een reactie.

Bij de opbouw van het themanummer zijn de in de ogen van de redactie meest fundamentele punten van kritiek zoals die uit de verschillende bijdragen naar voren komen, gebruikt als rode draad. Gehoopt wordt hiermee een constructieve discussie over dit belangrijke rapport te bevorderen, die is gericht op het bereiken van een situatie waarin toezicht op publieke belangen op alle overheidsniveaus kan rekenen op vertrouwen bij de politiek, de onder toezicht gestelden en bovenal de burgers.

\section{Blik is te veel naar binnen gericht}

Jonathan Zeitlin gaat in zijn bijdrage in op de 'toezichtparadox' en de vier verschuivingen die volgens de WRR nodig zijn voor een verruimd perspectief op toezicht. Hoewel hij deze kernopgaven onderschrijft, is er volgens hem meer nodig voor een overtuigende vernieuwingsstrategie van het Nederlandse toezicht. Hiertoe zou meer en ook anders dan nu door de WRR is gedaan, moeten worden gekeken naar en geleerd van hoe het toezicht buiten Nederland zich heeft ontwikkeld. Om te beginnen mist hij in het rapport een aanpak waarbij de vier kernopgaven worden geïntegreerd tot een elkaar versterkende architectuur. Hij heeft hierbij het oog op 'experimentalism', een innovatieve vorm van toezicht op basis van een iteratief proces van voorlopige doelstellingen en revisie ervan aan de hand van wat wordt geleerd van ervaringen met alternatieve benaderingen om de doelen in verschillende lokale omgevingen te bereiken. Dit vereist onder meer een verbinding tussen toezicht op diverse bestuursniveaus en met toezicht door private organisaties. Deze vorm van toezicht wordt inmiddels binnen de EU en de VS in toenemende mate toegepast.

Voorts toont hij zich kritisch over de manier waarop in het rapport wordt gekeken naar toezicht en toezichtnetwerken op Europees niveau. Namelijk meer als 
een 'complicerende factor' en bron van onnodige 'beperkingen' voor nationale toezichthouders of zelfs als 'Trojaanse paarden' die de weg bereiden voor verdere Europese integratie, dan als iets waar de nationale toezichthouders veel aan kunnen hebben. Deze naar binnen gerichte en defensieve benadering acht hij temeer verrassend omdat Europees toezicht in diverse sectoren waaraan in het rapport aandacht is besteed, uitgesproken experimentele trekken heeft. Door er met andere ogen naar te kijken, zou hiervan veel geleerd kunnen worden.

\section{Maatschappelijke rol van toezichthouder te gemakkelijk voorgesteld}

Alex Brenninkmeijer gaat in zijn bijdrage vanuit het perspectief van de burger (in de vorm van een interview) uitgebreid in op de maatschappelijke context waarin toezicht op publieke belangen zich afspeelt. Die context zou volgens hem bepalend moeten zijn voor de kijk op toezicht. Een eerste kenmerk van die context is dat zij veel ruimer is dan het rijksniveau: het gaat om globaal, Europees, nationaal, regionaal, lokaal en de verbinding daartussen. Een ander kenmerk is complexiteit, vaak overgaand in chaos. Hierbij past geen toezicht als vorm van verticale beheersing van de samenleving. Het toezicht moet aansluiting zoeken bij horizontale verbanden in de netwerksamenleving, zoals de WRR ook constateert, en moet zich nadrukkelijker baseren op waarden en standaarden (publieke belangen). Dat het toezicht zoals dit nu is georganiseerd en wordt uitgeoefend, de burgers helemaal niet aanspreekt, komt volgens Brenninkmeijer mede doordat toezichthouders zich een beetje schuilhouden. Om onafhankelijk te kunnen zijn, moeten toezichthouders los worden gemaakt van de ministeriële kolom waartoe ze nu behoren en van de ministeriële verantwoordelijkheid voor toezicht op rijksniveau. Dit vereist een andere manier van verantwoording dan via een politieke bestuurder. Dan kan en moet de toezichthouder een speler worden in een netwerkstructuur, uitgaan van professionele waarden en verbinding zoeken met de burger. De kern van zijn taak zal dan moeten zijn: het voeren van een lastig gesprek met degene op wie toezicht wordt gehouden, met de opdrachtgevers en uiteindelijk ook met burgers. Met als keerzijde dat hij zich ook moet verantwoorden voor zijn handelen binnen de netwerkstructuur waarin hij functioneert.

De maatschappelijke rol van de toezichthouder wordt door Chris Fonteijn belicht vanuit het perspectief van de toezichthouder, i.c. ACM. Hij deelt de opvatting van de WRR dat voor het behartigen van publieke belangen de toezichthouder ook gebruik moet kunnen maken van niet-formele middelen als compliance assistence, marktstudie, communicatie e.d. In een tijd waarin de overheid beslissingen ten aanzien van publieke belangen meer en meer overlaat aan marktpartijen en organisaties, is de rol van de toezichthouder des te meer van belang. Hij zal erop moeten blijven toezien dat die beslissingen vallen binnen nationale en Europese wettelijke kaders. Dat kan betekenen dat de uitkomst van een weging van publieke belangen binnen het mededingings-/reguleringskader anders uitpakt dan politiek-bestuurlijk wenselijk is. Fonteijn staat achter de aanbevelingen van de WRR om de reflectieve functie van de toezichthouder te versterken en ruimte te schep- 
pen voor verantwoording aan de buitenwereld, in het bijzonder het parlement. Een onafhankelijke positie en oordeelsvorming acht hij hierbij onontbeerlijk. Judith van Erp en Karin van Wingerde gaan eveneens in op de door de WRR bepleite rol van de toezichthouder binnen het maatschappelijk krachtenveld. De visie van de WRR sluit volgens hen aan bij de theoretische stroming responsive regulation, die verwacht dat door middel van een dialoog met onder toezicht gestelde organisaties een beter nalevingsniveau en een betere beheersing van maatschappelijke risico's kunnen worden gerealiseerd. Toezicht is dan niet langer een zaak van de toezichthouder. Derde partijen krijgen ook een rol bij het vergaren van informatie over het gedrag van bedrijven en instellingen en een stem in de discussie en besluitvorming over de inzet van toezicht. Dit lijkt mooi, maar de auteurs plaatsen kritische kanttekeningen bij de veronderstelde werking van dit concept in de praktijk. Zij concluderen dat de implicaties van het WRR-rapport dan ook veel groter zijn dan op het eerste gezicht lijkt.

Annetje Ottow en Madeleine de Cock Buning constateren dat in het rapport de juridische aspecten van het toezicht onderbelicht zijn gebleven. Dit komt volgens hen doordat de WRR heeft gekozen voor een bestuurlijk en beleidsmatig perspectief, met een sterke nadruk op de doelen van het toezicht. Hierdoor wordt onvoldoende rekening gehouden met het feit dat het doen en nalaten van de toezichthouder steeds aan een juridische toetsing is onderworpen. De eerste vraag die zich bij het toezicht telkens aandient, is immers op basis van welke wettelijke grondslag de toezichthouder handelt. Bij die toetsing speelt de uitleg, de interpretatie van die grondslag, niet zelden een belangrijke rol. In de praktijk levert de interpretatie vaak discussie op; de meningen van rekkelijken en preciezen kunnen sterk verschillen. Hierbij komt dat het toezicht voortdurend worstelt met het spanningsveld tussen de instrumentele functie van het bestuursrecht - dienstbaar aan beleidsmatige doelstellingen - aan de ene kant en de waarborgfunctie - dienstbaar aan rechtsbescherming - aan de andere kant. Dit alles brengt mee dat het bestuurs(proces)recht als essentieel referentie- en toetsingskader voor toezicht beperkingen stelt aan de ruimte voor experimenten of vernieuwingen en daarmee ook aan een grotere maatschappelijke rol van de toezichthouder. De wetgever, de toezichthouder en de rechter, die het toezicht moet toetsen, staan volgens de auteurs dan ook voor de uitdaging om een juiste balans te vinden tussen de toepassing van de functionele benadering - waarbij het vereiste van doeltreffendheid een belangrijke overweging is - en het voldoen aan de legaliteits- en waarborgeisen.

\section{Oplossing voor dilemma's van de politiek schiet tekort}

Het lezen van het WRR-rapport vanuit het perspectief van de politiek heeft Hans de Bruijn tot de bevinding gebracht dat de Raad op z'n minst twee tikken uitdeelt aan de politiek. Politici respecteren onvoldoende de onafhankelijkheid van de toezichthouder en zijn te vaak gefixeerd op de kosten en lasten van toezicht. Hiermee doet de WRR volgens hem geen recht aan de dilemma's waarvoor toezicht politici plaatst. Dit oordeel onderbouwt hij met kritische kanttekeningen bij de 
wijze waarop de WRR is gekomen tot zijn standpunten over onafhankelijkheid, nadruk op kosten en lasten van toezicht en publieke belangen als uitgangspunt voor toezicht.

In zijn bijdrage toont Paul de Bijl zich minder kritisch, maar hij laat wel doorschemeren dat de WRR z.i. te gemakkelijk denkt over de bereidheid van de politiek om het door de Raad bepleite verruimde perspectief op toezicht over te nemen. Hij onderschrijft de door de WRR gemaakte keuze voor 'publieke belangen' als ijkpunt voor de functie en de inrichting van toezicht. Hiermee wordt volgens hem duidelijk gemaakt dat zij niet alleen leidend moeten zijn voor toezichthouders. Dit ijkpunt disciplineert ook politici en beleidsmakers om verder te kijken, om zich te richten op de welvaartseffecten van toezicht, en zo recht te doen aan de maatschappelijke complexiteit en dynamiek. Het disciplineert hen ook om publieke verantwoordelijkheden niet uit te hollen - volgens hem een reëel gevaar in het licht van de diagnose door de WRR. De politieke leiders dienen uit te stralen dat zij de publieke taken van toezicht respecteren en ondersteunen. Alleen dan kunnen de aanbevelingen van de WRR levensvatbaar worden gemaakt. Zo ver zijn we nog lang niet, is zijn conclusie.

De bijdrage van Margot Aelen en Gustaaf Biezeveld sluit hierop aan. De constatering van de WRR dat onafhankelijkheid bepaald geen 'rustig bezit' is voor toezichthouders, was voor hen aanleiding te kijken naar de voornaamste redenen voor onafhankelijkheid en de oorzaken van de 'onrust'. De wens van de politiek controle te hebben over wat de toezichthouder doet - onder verwijzing naar het belang van democratische controle en legitimatie - staat tot nu toe in de weg aan erkenning van onafhankelijkheid van de politiek als een beginsel van toezicht. Onder verwijzing naar het belang van democratische controle en legitimatie houdt de politiek door diverse beïnvloedingsstructuren de toezichthouder in de greep. Die kennelijke behoefte aan grip op het toezicht verklaart enerzijds waarom de politieke wil ontbreekt om niet-onafhankelijke toezichthouders, zoals inspectiediensten van het Rijk en decentrale overheden, onafhankelijk te maken, en anderzijds waarom pogingen worden gedaan om, waar wel sprake is van onafhankelijkheid, zoals bij markttoezichthouders, deze in te perken. Dat onafhankelijke toezichthouders hierdoor onrustig worden, is begrijpelijk. Dit vraagt om een oplossing die verdergaat dan door de WRR wordt aangereikt. De auteurs doen hiervoor een voorstel.

\section{Onvoldoende aandacht voor toezicht in de praktijk}

Ko de Ridder (o.a. voorzitter van de beroepsvereniging voor inspecteurs, Vide) is, vanuit het perspectief van de toezichthouder, kritisch over het in het rapport ontbreken van gerichte aandacht voor de toezichtpraktijk en degenen die hierin werkzaam zijn, de inspecteurs. Als medewerkers van toezichthoudende instanties zijn zij het immers die de voorstellen van de WRR over veranderingen in de rol van de toezichthouder (in de betekenis van instantie) in de praktijk moeten brengen. In de afgelopen tien jaar hebben zij al heel wat te verstouwen gekregen in de vorm van bezuinigingen, reorganisaties en telkens wisselende opvattingen over 
toezicht. Een beschouwing over hoe zij hiermee zijn omgegaan en de flexibiliteit die zij hierbij hebben getoond, had in het rapport niet mogen ontbreken. Ook het geheel aan kwalificaties en competenties waarover een inspecteur moet beschikken om zijn of haar taak goed te kunnen vervullen, blijft sterk onderbelicht in het rapport. In het verlengde hiervan stelt De Ridder dat de WRR ten onrechte geen aandacht heeft besteed aan de opleiding van de inspecteur. Er is volgens hem dringend behoefte aan een eenduidige benadering van de opleiding van 'de' toezichthouder, met eindtermen die gebaseerd zijn op een beroepsprofiel met gedefinieerde kwalificaties en competenties. Voor een meer coherente en omvattende aanpak zou een voorbeeld kunnen worden genomen aan de Academie voor Wetgeving annex de Academie voor Overheidsjuristen. Een model dat z.i. voldoende inspiratie bevat voor één alomvattend instituut voor de opleiding van medewerkers van toezichthoudende instanties.

Het artikel van Annette Roeters en Jos Verkroost, die beiden werkzaam zijn bij de Inspectie van het Onderwijs, sluit hierop aan. Ook zij constateren in het rapport een grote afstand tot de uitvoerders van het toezicht en de zaken die zij in de dagelijkse praktijk tegenkomen. Het rapport behoeft aanvulling op het punt van het leggen van een verbinding met de medewerkers van de inspecties die het werk op straat, in de bedrijven en in de instellingen uitvoeren en aan de door de WRR bepleite reflectie gestalte moeten geven. Om dit gemis te compenseren geven zij een aantal eigen waarnemingen uit de afgelopen jaren weer.

Ferdinand Mertens, ten slotte, vraagt zich af of hij zich als inspecteur-generaal geholpen zou hebben gevoeld door het rapport. Hiertoe maakt hij een tour d'horizon, stipt aan wat hij mist en waardeert de verschillende elementen van het rapport deels positief, deels minder positief. Dit brengt hem tot de slotsom dat zijn antwoord als inspecteur-generaal zou zijn: onvoldoende, omdat de WRR nog niet klaar is. De belangrijkste en minst uitgewerkte inzichten zouden daarom verder door de Raad moeten worden opgepakt.

Het themanummer wordt afgesloten met een repliek vanuit de WRR door André Knottnerus, Meike Bokhorst, Peter de Goede en Pieter Welp. 